\title{
Association of characteristics of delivery and medical conditions during the first month of life with developmental defects of enamel
}

\author{
Mahtab Memarpour', Ali Golkari ${ }^{*}$ and Reihaneh Ahmadian ${ }^{3}$
}

\begin{abstract}
Background: Developmental defects of enamel (DDE) may be influenced by health problems and illness in children. The aim of the study was to identify the main characteristics of birth (delivery) and adverse medical conditions during the first month of life that may be related to DDE in permanent teeth.

Methods: 1000 schoolchildren between the ages of 9 and 11 years were selected for this cross-sectional study by multistage randomization from four educational zones in Shiraz in 2013. Intraoral examination was used to diagnose DDE according to World Health Organization screening guidelines and the Modified DDE Index. The data on seven birth factors as well as health and nutritional conditions during the first month of life were collected by a questionnaire completed by the parents, and were analyzed with the chi-squared test, Spearman's correlation and binary logistic regression.

Results: 469 (48.2\%) out of 974 schoolchildren had at least one permanent tooth with DDE. The defects were significantly related with Apgar score at birth $<7(p=0.003)$ and illness during the first month $(p=0.035)$. The frequency of DDE was significantly lower in the third child in families compared to the first and second child $(p=0.005)$. However, DDE showed no significant relationship with gestational age, delivery type, birth weight, gender or type of feeding during early infancy.
\end{abstract}

Conclusions: Three associated factors were identified (birth Apgar score, illness during the first month of life, birth order) for DDE in permanent teeth. No specific illness was found to be significantly associated with DDE.

Keywords: Dental enamel, Infant, Apgar score, Birth order, Permanent teeth

\section{Background}

Tooth enamel may be affected by factors that occur before or after tooth eruption or during tooth development. The factors that occur during tooth development are caused by disturbances in the formation and calcification phases of tooth enamel development, and can lead to developmental defects of enamel (DDE) before tooth eruption [1]. These defects are divided in two main groups: hypomineralization (change in the quality of the enamel) and hypoplasia (change in the quantity). In hypomineralization, changes in enamel transparency are visible as staining or opacity.

\footnotetext{
*Correspondence: golkaria@sums.ac.ir

${ }^{2}$ Department of Dental Public Health, School of Dentistry, Shiraz University of Medical Sciences, Shiraz, Iran

Full list of author information is available at the end of the article
}

Epidemiological studies have reported that the prevalence of DDE ranges widely between $23 \%$ and $49 \%$ in primary teeth and between $18 \%$ and $63 \%$ in permanent teeth [2-11]. DDE may cause problems for children such as increased tooth sensitivity, poor appearance [11,12], increased risk of dental caries [7,13-18] and dental attrition [19].

DDE may develop because of factors that affect the formation or secretion of enamel. Factors associated with DDE can be categorized as localized or generalized, and generalized factors can be further divided into environmental and hereditary, both of which influence enamel during prenatal, neonatal and postnatal development [20]. Chemical elements and medicines administered to young children or their mothers during pregnancy have been cited as other important factors [21,22]. Among 
these factors, some occur before birth or during the first months of infancy, and can affect children's general health as well as their future oral and dental health. Earlier studies reported that low birth weight is associated with an increased frequency of enamel hypoplasia and DDE in primary teeth $[23,24]$. Also some conditions may cause DDE or molar-incisor hypomineralization in permanent teeth [25,26]. In addition, low Apgar score is a high risk factor for dental caries in preschoolchildren [27]. Apgar score is a rapid method to evaluate the clinical status of newborn infants [28]. Research has shown the DDE in primary teeth may be related with a low Apgar score, inadequate parenteral nutrition or multiple births [29].

Medical problems during the perinatal and postnatal periods are other factors that can lead to the development of DDE, in addition to those identified in previous studies [30,31]. A history of infectious or congenital diseases in children is a predisposing factor for enamel hypoplasia or DDE in the primary or permanent teeth $[7,32,33]$. Most of these diseases and medical conditions appear to act not directly on the ameloblasts, but by affecting the child's nutrition and growth; as a result, ameloblasts do not obtain the nutrients they need to secrete enamel.

Because DDE occur due to changes during tooth development and cause problems for patients, it is important to identify adverse conditions during tooth formation. However, most studies have been designed to discover associations between prenatal and perinatal conditions and DDE, molar-incisor hypomineralization or enamel hypoplasia in primary teeth $[22-24,30,31]$. Only a few studies have considered the permanent dentition [25,26], and most of them have considered specific diseases only [33]. In an effort to consider a variety of adverse conditions that can affect children at a specific period of time and that may be factors associated with DDE in the permanent dentition, this study investigated the effect of birth characteristics and adverse medical conditions during the first month of life on the presence of DDEs in permanent teeth in a representative group of 9- to 11-year-old children.

\section{Methods}

This retrospective study was designed and conducted during the 2013 school year, and the participants were 9- to 11-year-old children who were attending primary schools in Shiraz. Ethical approval was obtained from Shiraz University of Medical Sciences and the Shiraz Educational Head Office (Grant no. 8591024). The children were selected by multistage randomized sampling. The city was divided geographically into four areas based on the zones established by the Educational Head Office. Then four primary schools were randomly selected in each zone (two girls' schools and two boys' schools, as schools are segregated according to gender in Iran). At each school 80 pupils were selected randomly in the fourth and fifth grades. If the total number of fourth and fifth graders at a given school was less than 80 , all students were included, and if the total number was more than 80 , students were selected randomly by using simple randomization. The main inclusion criterion was age between 9 years, 0 months and 11 years, 11 months. All children had resided in Shiraz city since birth to the time of study, and the level of fluoride in drinking water was approximately the same $(0.3-0.7 \mathrm{ppm})$ throughout the city. The exclusion criteria were systemic or chronic diseases such as heart disease, congenital physical or mental disability, full-coverage restoration in a permanent tooth, filling or fissure sealant on the buccal or palatal surfaces, orthodontic brackets, lack of parental consent to participate in research and lack of cooperation with the examination. Also questionnaires that were not returned or in which more than one item was left blank were excluded from the study.

A specially-designed questionnaire for the parents was developed. The aims and procedures of the study were explained and participants' privacy was ensured in the consent form. The parents were asked to complete and return the questionnaire only if they consented to their child's inclusion in the study. A phone number was provided in case they needed more information about the study or the questionnaire. Parents who provided their consent for their child to participate were asked to complete the questionnaire. The items on birth conditions were based on the Health Status Evaluation Form that must be completed and filed by the attending doctor or midwife at birth. The parents were asked to refer to their children's birth record when answering these questions. The data were collected in two parts:

1. Demographics (date of birth, gender, place of residence since birth), type of delivery (natural, aided or cesarean), birth weight (less than 2500 , between 2500 and 4000, and more than 4000 grams), gestational age (less than 38 , between 38 and 42, and more than 42 weeks), birth Apgar score (less than 7 and 7 or more) [28], birth order (first child, second child, or third/later child), number of babies delivered (singleton, twins or triplets) and mother's age at delivery (less than 20 , between 20 and 35, and more than 35 years). In the second part of the questionnaire, the parents were asked about the type of infant feeding, name and duration of diseases (if any), and hospitalizations (if any) during the first month of life. This part of the questionnaire was completed by the parents.

2. DDE were recorded by the project investigators during intraoral examinations. 
After explaining the purposes of the study to the schoolchildren, information on oral health education was provided in groups. Each selected child who returned the signed consent form and questionnaire was given a toothbrush and toothpaste and asked to clean his/her teeth under supervision. Intraoral examination was performed by two senior dental students (after appropriate calibration) to record DDE. The examiners' evaluations were calibrated by having them examine 20 patients under supervision by the professor. Intra-examiner reliability was checked during the calibration sessions, and interexaminer reliability was alpha $=0.73$. The examiner first cleaned the teeth with sterile gauze, then examined all the permanent teeth with a disposable mirror, explorer and head light. The criteria for DDE were based on the instructions and oral health screening forms provided by the World Health Organization (1997) and the modified DDE index for screening studies (1987) [34]. In the present study, the number of children with at least one DDE was recorded. In addition the mean number of the teeth with DDE was calculated for the whole sample of children. The examinations were supervised by two faculty members with extensive experience in this subject, who also participated in the calibration process.

The SPSS (version PASW 18; IBM, USA) was used for data entry and analysis. The percentage of children with at least one DDE in a permanent tooth and the average number of permanent teeth with a DDE per child were calculated. The relationship between having a DDE in a permanent tooth and each of the characteristics of birth (type of delivery, birth weight, gestational age, birth Apgar score, birth order, number of babies delivered and mother's age at delivery) and the first month of infancy (feeding in the first months and illness in the first months) was analyzed with the chi-squared test. The relationships were assessed once again after adjustments. For this purpose, along with sex and number of permanent teeth present, all variables with a bivariate $p$ value less than 0.250 were entered in a binary logistic regression model to adjust for the effects of possible confounders. Spearman's correlation test was used to identify correlations between the duration (in weeks) of illness or hospitalization and the number of permanent teeth with DDE.

\section{Results}

A total of 974 (97\%) children (average age \pm standard deviation: $10.23 \pm 0.66$ years) who met the inclusion criteria participated in the study and returned their parents' completed questionnaire; 484 (49.7\%) were boys and 490 (50.7\%) were girls. 341 of the children attended a private school and the rest were from public schools (Table 1). Fourteen restored permanent teeth were excluded from the study; however these children were not excluded from the analysis. Ten children were excluded because their parents did not provide their informed consent, six were excluded because of blank items in their returned questionnaires, and four children were absent on the days of both visits to their school.

In all, 469 children (48.2\%) had at least one tooth with DDE. The percentage of boys (46.5\%) and girls (49.8\%) with DDE was similar, as was the percentage of children with DDE from public (48.5\%) and private schools (47.5\%). The average number of teeth with DDE per child was $2.13 \pm 3.48$. The difference among the four educational zones in the average number of teeth with DDE (range 1.9 to 2.13) was not statistically significant $(p=0.589)$. Neither was this average significantly different between sexes $(p=0.239)$ or between children from public and private schools $(\mathrm{p}=0.778)$.

Sixty-one (6.3\%) children had a birth Apgar score less than 7. Among them, 39 (63.9\%) had at least one DDE in a permanent tooth; the rate of DDE among those with a birth Apgar scored of 7 or more (913 children) was $47.1 \%$. The difference between the two groups was statistically significant $(\mathrm{p}=0.003)$, i.e., children born with an Apgar score of less than 7 were more likely to have DDE in their permanent dentition. Just below $50 \%$ of the children were the firstborn child in their family. About a quarter of the children were the second child, and the other quarter of children were the third child (or later) in the family. The percentage of DDE in their permanent teeth was $50.3 \%$ among firstborn children, $51.7 \%$ among second children, and $40.1 \%$ among children who were third or later in birth order. Thus, children in the third group were significantly less likely to have a DDE in their permanent teeth than the other two groups $(\mathrm{p}=$ 0.005). No other birth characteristic and no type of feeding was significantly related with the frequency of DDE in the permanent teeth (Table 2).

The parents of 144 children ( $14.8 \%$ of the total) reported that their child had a serious illness between birth and 1 month of age. Of this group, 81 children (56.3\%) had at least one permanent tooth with DDE. As shown in Table 2, this rate was significantly higher than the $46.7 \%$ rate in children with no reported illnesses during their first month of life $(\mathrm{p}=0.035)$. No specific disease was found to be more (or less) likely to be related with the presence of DDE. However, the number of DDE in the permanent teeth increased with the duration (in weeks) of the illness $(\mathrm{r}=0.423, \mathrm{p}=0.006)$.

As seen in Table 3, all factors found in the bivariate analysis to be significantly related with the likelihood of having a DDE in permanent teeth remained significant after adjustment. The regression models showed that children with an Apgar score of less than 7 were 2.32 times more likely than the others to develop a DDE (OR = 2.32, 95\% CI: 1.31-4.11, $\mathrm{p}=0.004)$. Children who were 
Table 1 Number of children by sex, school type and school zone

\begin{tabular}{lcccr}
\hline Sex & Zone & \multicolumn{2}{c}{ School type, total N (N with DDE,\% with DDE) } & \multirow{2}{*}{ Total } \\
\cline { 3 - 4 } & & Public & $39(16,43.6 \%)$ & $119(51,42.9 \%)$ \\
\hline Boys & 1 & $80(34,42.5 \%)$ & $48(22,45.8 \%)$ & $128(63,49.2 \%)$ \\
& 2 & $80(41,51.3 \%)$ & $41(15,36.6 \%)$ & $114(66,57.9 \%)$ \\
& 3 & $73(51,69.9 \%)$ & $43(22,51.2 \%)$ & $123(45,36.6 \%)$ \\
Girls & 4 & $80(23,28.8 \%)$ & $171(76,44.4 \%)$ & $484(225,46.5 \%)$ \\
& All & $313(149,47.6 \%)$ & $50(26,52.0 \%)$ & $130(62,47.7 \%)$ \\
& 1 & $80(36,45.0 \%)$ & $42(25,59.5 \%)$ & $122(66,54.1 \%)$ \\
& 2 & $80(41,51.3 \%)$ & $39(12,30.8 \%)$ & $119(36,30.3 \%)$ \\
Total & 3 & $80(24,30.0 \%)$ & $39(23,59.0 \%)$ & $119(80,67.3 \%)$ \\
\hline
\end{tabular}

In parentheses, the percentage of children with DDE in each group.

Table 2 Relationship between DDE in permanent teeth and birth conditions, type of feeding and illness in the first month of life

\begin{tabular}{|c|c|c|c|c|c|}
\hline Factor & Groups & $\begin{array}{l}\text { Number of children } \\
\text { in group }\end{array}$ & $\begin{array}{c}\text { Number of children } \\
\text { with DDE }\end{array}$ & $\begin{array}{l}\text { Percentage of children } \\
\text { with DDE }\end{array}$ & $\begin{array}{c}\text { p-value before any } \\
\text { adjustment }\end{array}$ \\
\hline \multirow[t]{3}{*}{ Delivery type } & Natural & 506 & 247 & 48.8 & \\
\hline & Aided & 11 & 8 & 72.7 & 0.182 \\
\hline & Cesarean & 414 & 191 & 46.1 & \\
\hline \multirow[t]{3}{*}{ Birth weight (g) } & $<2500$ & 94 & 42 & 44.7 & \\
\hline & $2500-4000$ & 763 & 367 & 48.1 & 0.639 \\
\hline & $>4000$ & 59 & 30 & 50.8 & \\
\hline \multirow{3}{*}{$\begin{array}{l}\text { Gestational age } \\
\text { (weeks) }\end{array}$} & $<38$ & 308 & 151 & 49.0 & \\
\hline & $38-42$ & 489 & 232 & 47.4 & 0.842 \\
\hline & $>42$ & 21 & 11 & 52.4 & \\
\hline \multirow[t]{2}{*}{ Birth Apgar score } & $<7$ & 61 & 39 & 63.9 & 0.011 \\
\hline & $\geq 7$ & 913 & 430 & 47.1 & \\
\hline \multirow[t]{3}{*}{ Birth order } & $1 s t$ & 453 & 228 & 50.3 & \\
\hline & 2nd & 240 & 124 & 51.7 & 0.016 \\
\hline & 3rd or later & 237 & 95 & 40.1 & \\
\hline \multirow{2}{*}{$\begin{array}{l}\text { Number of newborns } \\
\text { deliveries }\end{array}$} & Single & 953 & 458 & 48.1 & 0.539 \\
\hline & $\begin{array}{l}\text { Multiple (Twins or } \\
\text { triplets) }\end{array}$ & 20 & 11 & 55.0 & \\
\hline \multirow{3}{*}{$\begin{array}{l}\text { Mother's age at } \\
\text { delivery (years) }\end{array}$} & $<20$ & 167 & 79 & 47.3 & \\
\hline & $20-35$ & 715 & 340 & 47.6 & 0.948 \\
\hline & $>35$ & 44 & 22 & 50.0 & \\
\hline \multirow{3}{*}{$\begin{array}{l}\text { Feeding in the first } \\
\text { month }\end{array}$} & Breast milk & 833 & 394 & 47.3 & \\
\hline & Formula & 37 & 17 & 45.9 & 0.429 \\
\hline & Both & 61 & 34 & 55.7 & \\
\hline \multirow{2}{*}{$\begin{array}{l}\text { Illness in the first } \\
\text { month }\end{array}$} & Yes & 144 & 81 & 56.3 & 0.035 \\
\hline & No & 830 & 388 & 46.7 & \\
\hline
\end{tabular}


Table 3 Association between DDE in permanent teeth and variables with a p-value less than 0.250 in the bivariate analysis, plus sex and the number of permanent teeth present

\begin{tabular}{|c|c|c|c|}
\hline & & Odds ratio $(95 \% \mathrm{Cl})$ & $\mathrm{p}$-value \\
\hline \multirow[t]{2}{*}{ Sex } & Boy & 1 & - \\
\hline & Girl & $1.33(1.02-1.74)$ & 0.037 \\
\hline Number of permanent teeth & & $0.98(0.95-1.01)$ & 0.152 \\
\hline \multirow[t]{3}{*}{ Delivery type } & Natural & 1 & - \\
\hline & Aided & $2.77(0.69-10.86)$ & 0.152 \\
\hline & Cesarean & $0.90(0.69-1.17)$ & 0.423 \\
\hline \multirow[t]{2}{*}{ Birth Apgar score } & $\geq 7$ & 1 & - \\
\hline & $<7$ & $2.32(1.31-4.11)$ & 0.004 \\
\hline \multirow[t]{3}{*}{ Birth order } & $1 s t$ & $1.57(1.13-2.17)$ & 0.007 \\
\hline & 2nd & $1.68(1.16-2.45)$ & 0.006 \\
\hline & 3rd or more & 1 & - \\
\hline \multirow[t]{2}{*}{ Illness in the first month } & No & 1 & - \\
\hline & Yes & $1.58(1.08-2.31)$ & 0.017 \\
\hline
\end{tabular}

their mothers' third child or later in birth order were significantly less likely to develop a DDE than firstborn $(\mathrm{p}=0.007)$ or secondborn children $(\mathrm{p}=0.006)$. Illness in the first month of life also remained significantly associated with having a DDE after adjustment $(\mathrm{OR}=1.58$, 95\% CI: 1.08-2.31, $\mathrm{p}=0.017)$. Moreover, regression analysis showed that girls were 1.33 times (95\% CI: $1.02-$ $1.74, \mathrm{p}=0.037)$ more likely to have a DDE than boys. The number of permanent teeth present showed no significant association with the risk of having a DDE. This was probably due to the fact that the permanent incisors and first molars had erupted in all children included in the present study. Therefore, if there had been a risk of having a DDE the lesion was most likely to appear in these teeth rather than in the premolars or canines.

\section{Discussion}

This study investigated the effects of factors during delivery and the first month of life on the subsequent appearance of DDE in the permanent teeth of children in the 4th and 5th grades of primary school in Shiraz. The overall prevalence of DDE was $48.2 \%$, which was close to the figures reported by others $[3,10,11]$. We selected this age group because in most children their permanent incisors and first molars had erupted, and most of the newly erupted teeth were not affected by attrition or erosion and therefore would show DDE more clearly than aged teeth.

The number of boys and girls was almost equal. The numbers of children from different educational zones were also similar. However, the number of children from private schools was lower than those from public schools. Although the percentage of boys and girls with a DDE in school zones 3 and 4 might have differed, the two areas offset each other and therefore no significant difference was seen between all boys and all girls in our sample.

The secretion phase of enamel development in the permanent dentition starts around birth [1]. The circumstances of birth and the first month of life are therefore important both as the starting point for enamel secretion and as periods of life that affect the child's nutrition and growth during subsequent years. Most previous studies of the risk factors for DDE analyzed the direct effects of illness and other adverse conditions. The "direct effects" of each associated factor are expected to affect the enamel that is being formed at the time when each factor occurred. The formation of most permanent teeth had not yet started during the age range (birth to 1 month) we investigated [35]. Nevertheless, "indirect effects" are also important to consider. In other words, birth and perinatal factors would be expected to affect the child's general health in later life [36]. Accordingly, DDE in the permanent dentition can be used as a marker of a child's general previous health status.

Apgar score is used to evaluate the infant's general health immediately after delivery [37]. We found that a low birth Apgar score may be related with DDE in the permanent teeth. The same result was reported earlier for primary teeth $[29,37]$. Among the factors that may affect Apgar score are gestational age, maternal medication, resuscitation, cardiorespiratory and neurologic conditions, infections, hypoxia, hypovolemia and preterm delivery [28].

Like other researchers, we found that DDE were more frequent in children with a history of illness during the first month of life than in children without this antecedent. Children with a history of respiratory infection, 
chickenpox congenital rubella or otitis reportedly had more in their primary teeth and permanent teeth $[7,32,33]$ than their peers without a history of these illnesses. Such illnesses may lead to hypocalcemia, hypoxia and pyrexia in the child or the mother [30]. This may be related with the effect of illness on enamel formation, or may reflect the influence of drugs such as amoxicillin, which can indirectly affect enamel [38].

We found no significant relationship between DDE and low birth weight or preterm delivery. Some studies reported these factors to be associated with DDE in the primary teeth $[23,24,29]$ or permanent teeth $[25,26]$. Their effect on primary dentition may be related to the fact that most enamel in the primary teeth is secreted before birth, so an adverse condition during gestation might affect birth weight and lead to DDE in the primary dentition.

The differences between our results and factors previously associated with DDE in the permanent teeth may be related to differences in the categories used to record low birth weight or gestational age $[25,27,39]$. For example, some researchers defined preterm delivery as a gestational age $\leq 36$ weeks, and defined low birth weight as $<1500 \mathrm{~g}$. In addition, the low numbers of children in some of the categories we used, such as low or high birth weight, instrumental delivery and multiple deliveries, may be another reason for the absence of significant differences between groups. For example, 8 out of 11 children with instrumental delivery had DDE, and the percentage frequency of $72.7 \%$ with DDE in this subgroup was much higher than the $48.2 \%$ average. The low number of children in this category thus probably accounted for the absence of significant differences compared to other subgroups.

We found that birth order was related with the prevalence of DDE in our sample. Third children had significantly fewer DDE than firstborn children, a finding that may be related to low birth weight, mother's age during pregnancy or nutritional deficiency $[40,41]$.

The response rate was about $98 \%$, which was relatively high considering the nature of the study. The results of this study can be assumed to be essentially unaffected by the data we excluded from analysis. A limitation of the present study was the use of a self-completed questionnaire to obtain information about circumstances during delivery and the first month of life. Birth conditions were recorded in the children's birth record, which is mandatory in Iran. These items in the questionnaire thus probably reflected accurate information. However, parents may not accurately recall events during the child's first months of life or may not have access to their child's perinatal medical record. The questionnaire items that depended on parents' recall may thus have been influenced by the variable reliability of the information our respondents provided. To overcome this limitation a cohort study would be needed, based on accurate childbirth and follow-up records in addition to information about the frequency of DDE.

\section{Conclusions}

This study found a prevalence of DDE in permanent teeth of $48.2 \%$ in children aged 9 to 11 years. There was a significant relationship between DDE and three early life factors that may affect tooth formation by having longterm effects on general health. A birth Apgar score less than 7 and illness during the first month of life had negative effects on enamel development. The duration of illness was more important than the specific type of illness. In addition, being the third child (or later) in a family was significantly related with a lower rate of DDE in comparison to being the firstborn child.

\section{Abbreviation}

DDE: Developmental defects of enamel.

\section{Competing interests}

The authors declare that they have no competing interests.

\section{Authors' contributions}

M: Conceptualized and designed the study, critically reviewed the manuscript, and approved the final manuscript as submitted. G: Initiated and designed the study, supervised data collection, carried out the initial analyses, reviewed the manuscript, and approved the final manuscript as submitted. A: Developed the data collection instrument, drafted the initial manuscript. All authors approved the final manuscript as submitted and agree to be accountable for all aspects of the work.

\section{Acknowledgements}

The authors thank the International Branch of Shiraz University of Medical Sciences for supporting this research (Grant no. 8591024). The authors also thank Dr M. Vossoughi of the Center for Research Improvement at the School of Dentistry for the statistical analysis and K. Shashok (AuthorAID in the Eastern Mediterranean) for improving the use of English in the manuscript. The manuscript is based on the thesis by Dr R. Ahmadian.

\section{Author details}

'Department of Pediatric Dentistry, School of Dentistry, Shiraz University of Medical Sciences, Shiraz, Iran. ${ }^{2}$ Department of Dental Public Health, School of Dentistry, Shiraz University of Medical Sciences, Shiraz, Iran. ${ }^{3}$ Student Research Committee, School of Dentistry, International Branch, Shiraz University of Medical Sciences, Shiraz, Iran.

Received: 22 May 2014 Accepted: 24 September 2014 Published: 1 October 2014

\section{References}

1. Alaluusua S: Aetiology of Molar-Incisor Hypomineralisation: a systematic review. Eur Arch Paediatr Dent 2010, 11:53-58.

2. Suckling GW, Pearce El: Developmental defects of enamel in a group of New Zealand children: their prevalence and some associated etiological factors. Community Dent Oral Epidemiol 1984, 12:177-184.

3. Corrêa-Faria P, Martins-Júnior PA, Vieira-Andrade RG, Oliveira-Ferreira F, Marques LS, Ramos-Jorge ML: Developmental defects of enamel in primary teeth: prevalence and associated factors. Int J Paediatr Dent 2013, 23:173-179.

4. Li Y, Navia JM, Bian JY: Prevalence and distribution of developmental enamel defects in the primary dentition of Chinese children 3-5 years old. Community Dent Oral Epidemiol 1995, 23:72-79.

5. Jälevik B, Klingberg G, Barregård L, Norén JG: The prevalence of demarcated opacities in permanent first molars in a group of Swedish children. Acta Odontol Scand 2001, 59:255-260. 
6. Montero MJ, Douglass JM, Mathieu GM: Prevalence of dental caries and enamel defects in Connecticut Head Start children. Pediatr Dent 2003, 25:235-259.

7. Ford D, Seow WK, Kazoullis S, Holcombe T, Newman B: A controlled study of risk factors for enamel hypoplasia in the permanent teeth. Pediatr Dent 2009, 31:382-388.

8. Kanagaratnam S, Schluter P, Durward C, Mahood R, Mackay T: Enamel defects and dental caries in 9-year-old children living in fluoridated and nonfluoridated areas of Auckland, New Zealand. Community Dent Oral Epidemiol 2009, 37:250-259.

9. Farsi N: Developmental enamel defects and their association with dental caries in preschoolers in Jeddah, Saudi Arabia. Oral Health Prev Dent 2010, 8:85-92.

10. Robles MJ, Ruiz M, Bravo-Perez M, González E, Peñalver MA: Prevalence of enamel defects in primary and permanent teeth in a group of schoolchildren from Granada (Spain). Med Oral Patol Oral Cir Bucal 2013, 18:e187-e193.

11. Seow WK, Ford D, Kazoullis S, Newman B, Holcombe T: Comparison of enamel defects in the primary and permanent dentitions of Children from a low-fluoride District in Australia. Pediatr Dent 2011, 33:207-212.

12. Jälevik B, Klingberg GA: Dental treatment, dental fear and behaviour management problems in children with severe enamel hypomineralization of their permanent first molars. Int J Paediatr Dent 2002, 12:24-32.

13. Pascoe L, Seow WK: Enamel hypoplasia and dental caries in Australian aboriginal children: prevalence and correlation between the two diseases. Pediatr Dent 1994, 16:193-199.

14. Li Y, Navia JM, Bian JY: Caries experience in deciduous dentition of rural Chinese children 3-5 years old in relation to the presence or absence of enamel hypoplasia. Caries Res 1996, 30:8-15.

15. Lai PY, Seow WK, Tudehope DI, Rogers Y: Enamel hypoplasia and dental caries in very-low birth weight children: a case-controlled, longitudinal study. Pediatr Dent 1997, 19:42-49.

16. Milgrom P, Riedy CA, Weinstein P, Tanner AC, Manibusan L, Bruss J: Dental caries and its relationship to bacterial infection, hypoplasia, diet, and oral hygiene in 6- to 36-month-old children. Community Dent Oral Epidemiol 2000, 28:295-306.

17. Oliveira AF, Chaves AM, Rosenblatt A: The influence of enamel defects on the development of early childhood caries in a population with low socioeconomic status: a longitudinal study. Caries Res 2006, 40:296-302.

18. Hong L, Levy SM, Warren JJ, Broffitt B: Association between enamel hypoplasia and dental caries in primary second molars: a cohort study. Caries Res 2009, 43:345-353.

19. Kazoullis S, Seow WK, Holcombe T, Newman B, Ford D: Common dental conditions associated with dental erosion in schoolchildren in Australia. Pediatr Dent 2007, 29:33-39.

20. Small BW, Murray JJ: Enamel opacities: prevalence, classifications and aetiological considerations. J Dent 1978, 6:33-42.

21. Billings RJ, Berkowitz RJ, Watson G: Teeth. Pediatrics 2004, 113:1120-1127.

22. Jan J, Sovcikova E, Kocan A, Wsolova L, Trnovec T: Developmental dental defects in children exposed to PCBs in eastern Slovakia. Chemosphere 2007, 67:S350-S354.

23. Nelson S, Albert JM, Geng C, Curtan S, Lang K, Miadich S, Heima M, Malik A, Ferretti G, Eggertsson H, Slayton RL, Milgrom P: Increased enamel hypoplasia and very low birthweight infants. J Dent Res 2013, 92:788-794

24. Pinho JR, Filho FL, Thomaz EB, Lamy ZC, Libério SA, Ferreira EB: Are low birth weight, intrauterine growth restriction, and preterm birth associated with enamel developmental defects. Pediatr Dent 2012, 34:244-248.

25. Nelson S, Albert JM, Lombardi G, Wishnek S, Asaad G, Kirchner HL, Singer LT: Dental caries and enamel defects in very low birth weight adolescents. Caries Res 2010, 44:509-518.

26. Brogårdh-Roth S, Matsson L, Klingberg G: Molar-incisor hypomineralization and oral hygiene in 10- to-12-yr-old Swedish children born preterm. Eur J Oral Sci 2011, 119:33-39.

27. Sanders AE, Slade GD: Apgar score and dental caries risk in the primary dentition of five year olds. Aust Dentl J 2010, 53:260-267.

28. American Academy of Pediatrics, Committee on Fetus and Newborn; American College of Obstetricians and Gynecologists and Committee on Obstetric Practice: The Apgar score. Pediatrics 2006, 117:1444.
29. Velló MA, Martínez-Costa C, Catalá M, Fons J, Brines J, Guijarro-Martínez R: Prenatal and neonatal risk factors for the development of enamel defects in low birth weight children. Oral Dis 2010, 16:257-262.

30. Lygidakis NA, Dimou G, Marinou D: Molar-incisor-hypomineralisation (MIH). a retrospective clinical study in Greek children. II. Possible medical aetiological factors. Eur Arch Paediatr Dent 2008, 9:207-217.

31. Chaves AM, Rosenblatt A, Oliveira OF: Enamel defects and its relation to life course events in primary dentition of Brazilian children: a longitudinal study. Community Dent Health 2007, 24:31-36.

32. Bhatia SK, Goyal A, Dubey M, Kapur A, Ritwik P: Congenital Rubella Syndrome: dental manifestations and management in a 5 year old child. J Clin Pediatr Den 2012, 37:71-75.

33. Arrow P: Risk factors in the occurrence of enamel defects of the first permanent molars among schoolchildren in Western Australia. Community Dent Oral Epidemiol 2009, 37:405-415.

34. Clarkson J, O'Mullance D: A modified DDE Index for use in epidemiological studies of enamel defects. J Dent Res 1989, 68:445-450.

35. Reid DJ, Dean MC: Variation in modern human enamel formation times. J Hum Evol 2006, 50:329-346.

36. Ben-Shlomo Y, Kuh D: A life course approach to chronic disease epidemiology: conceptual models, empirical challenges and interdisciplinary perspectives. Int J Epidemio/ 2002, 31:285-293.

37. Aminabadi NA, Farahani RM, Gajan EB: Apgar index as a correlate of enamel defects of primary dentition. Oral Health Prev Dent 2008, 6:331-335.

38. Hong L, Levy SM, Warren JJ, Dawson DV, Bergus GR, Wefel JS: Association of amoxicillin use during early childhood with developmental tooth enamel defects. Arch Pediatr Adolesc Med 2005, 159:943-948.

39. Aine L, Backström MC, Mäki R, Kuusela AL, Koivisto AM, Ikonen RS, Mäki M: Enamel defects in primary and permanent teeth of children born prematurely. J Oral Pathol Med 2000, 29:403-409.

40. Ghaemmaghami SJ, Nikniaz L, Mahdavi R, Nikniaz Z, Razmifard F, Afsharnia F: Effects of infants' birth order, maternal age, and socio-economic status on birth weight. Saudi Med J 2013, 34:949-953.

41. Wells JC, Hallal PC, Reichert FF, Dumith SC, Menezes AM, Victora CG: Associations of birth order with early growth and adolescent height, body composition, and blood pressure: prospective birth cohort from Brazil. Am J Epidemiol 2011, 174:1028-1035.

doi:10.1186/1472-6831-14-122

Cite this article as: Memarpour et al:: Association of characteristics of delivery and medical conditions during the first month of life with developmental defects of enamel. BMC Oral Health 2014 14:122.

\section{Submit your next manuscript to BioMed Central and take full advantage of:}

- Convenient online submission

- Thorough peer review

- No space constraints or color figure charges

- Immediate publication on acceptance

- Inclusion in PubMed, CAS, Scopus and Google Scholar

- Research which is freely available for redistribution 